\title{
A Cultura de Segurança em Estruturas Residenciais para Pessoas Idosas
}

\begin{abstract}
José Resende ${ }^{1}$, Graça Quaresma² e Pedro Lucas ${ }^{3}$
${ }^{1}$ MScN, RN, Unidade de Ensino, Formação e Investigação da Saúde Militar, Lisboa, Portugal | jrese@live.com | https://orcid.org/0000-0001-6354-3756

${ }^{2} \mathrm{MScN}, \mathrm{RN}$, Nursing Research, Innovation and Development Centre of Lisbon (CIDNUR).

Nursing School of Lisbon. Lisbon. Portugal. Centro Hospitalar e Universitário de Lisboa

Central, Lisboa, Portugal | mgquaresma@esel.pt | https://orcid.org/0000-0001-8567-0983

${ }^{3} \mathrm{PhD}, \mathrm{MSc}, \mathrm{MScN}, \mathrm{RN}$, Nursing Research, Innovation and Development Centre of Lisbon (CIDNUR). Nursing School of Lisbon. Lisbon. Portugal | prlucas@esel.pt | https://orcid.org/0000-0002-2560-7306

Resumo. Introdução: Desde a sua génese que a enfermagem valoriza a segurança do paciente. No entanto, a sua importância teve um grande impulso com o relatório do Institute of Medicine "To Err is Human", no ano 1999. A cultura de segurança do paciente em estruturas residenciais para pessoas idosas (ERPI), ainda pouco estudada, merece ser desenvolvida com vista à melhoria da qualidade dos cuidados; Objetivo: Analisar a evidência científica sobre a cultura de segurança do paciente nos lares de idosos; Critérios de inclusão / Métodos: Participantes: Cuidadores nos lares de idosos. Conceito: Cultura de Segurança do Paciente. Contexto: ERPI; Estratégia de pesquisa: Revisão integrativa da literatura, pesquisa de estudos através da CINHAL e MEDLINE e com recurso ao Google Scholar e repositórios de dissertações. Complemento de pesquisa nas referências dos estudos integralmente analisados. Definiu-se o período temporal entre 2015 e 2020 e a inclusão de artigos com texto completo; Resultados: Selecionaram-se 12 artigos referentes a estudos sobre a cultura de segurança do paciente de diferentes realidades e de diferentes países; Discussão: Os colaboradores das ERPI têm uma apreciação geral da segurança do paciente positiva. A cultura de segurança do paciente tem uma correlação com a qualidade dos cuidados prestados. Existem áreas transversalmente deficitárias nos lares de idosos, relacionadas com os recursos humanos e com a notificação de eventos adversos. Os gestores das estruturas para pessoas idosas revelam perceção geral da segurança dos residentes mais favorável que os colaboradores mais próximos dos cuidados; Conclusões: A evidência científica quanto à cultura de segurança do paciente nas ERPI é escassa em Portugal. A complexidade da população das ERPI, a influência multiprofissional e os défices estruturais em áreas importantes como a dos recursos humanos, remetem para a necessidade de novos estudos, principalmente qualitativos, e para um conjunto de intervenções emergentes que conduzam à melhoria da cultura de segurança do paciente $e$ da qualidade dos cuidados prestados nestas estruturas.
\end{abstract}

Palavras-chave: Casa de saúde; Segurança do doente; Cuidadores; Gestão da Segurança; Enfermagem.

\section{The Culture of Patient Safety in Nursing Homes}

Abstract: Introduction: Since its inception, nursing has valued patient safety. However, its importance was greatly boosted by the Institute of Medicine's report "To Err is Human", in 1999. The culture of patient safety in nursing homes, still little studied, deserves to be developed with a view to improving quality of care; Objective: To analyze the scientific evidence on the culture of patient safety in nursing homes; Inclusion criteria: Participants: Caregivers in nursing homes. Concept: Culture of Patient Safety. Context: Nursing home; Research strategy: Integrative literature review, study research through CINHAL and MEDLINE and using Google Scholar and dissertation repositories. Complement of research in the references of the studies fully analyzed. The time period between 2015 and 2020 was defined and the inclusion of articles with full text; Results: 12 articles were selected referring to studies on the culture of patient safety from different realities and from different countries; Discussion: Home staff have a positive overall assessment of patient safety. The culture of patient safety has a correlation with the quality of care provided. There are transversally deficient areas in nursing homes, related to human resources and the notification of adverse events. The managers of nursing homes reveal a general perception of the safety of residents that is more favorable than those closest to the care; Conclusion: The scientific evidence regarding the culture of patient safety in nursing homes is scarce in Portugal. The complexity of the population of nursing homes, the multiprofessional influence and structural deficits in important areas, such as staff, point to the need for further studies, mainly qualitative, and a set of emerging interventions that lead to an improvement in the culture of patient safety and the quality of care provided in these structures.

Keywords: Nursing Home; Patient Safety; Caregivers; Safety Management, Nursing. 


\section{Introdução}

A relevância atribuída à cultura de segurança do paciente (CSP) e ao seu efeito nos resultados teve um importante impulso com o relatório do Institute of Medicine (IOM) "To Err is Human", em 1999 (DiCuccio, 2015). Porém, a enfermagem sempre teve um papel histórico na promoção da segurança do paciente (SP) (Kowalski \& Anthony, 2017).

Quando falamos de estruturas residenciais para pessoas idosas (ERPI), encontramos uma grande diversidade, não só na dimensão e na organização das estruturas, mas também o próprio perfil dos seus residentes. A complexidade dos estados de saúde e funcional das pessoas idosas institucionalizadas, quando associada aos défices estruturais e sistémicos dos lares de idosos, dita a inevitabilidade de um maior investimento numa área com uma imensa margem de melhoria.

Nessa perspetiva, e considerando-a como ponto de partida, a presente revisão integrativa da literatura tem como objetivo analisar a evidência científica sobre a CSP nas ERPI.

Ao longo da sua história, os enfermeiros, num rápido e informado reconhecimento da realidade, apontam caminhos para a qualidade e segurança dos cuidados, enquanto objetivo primário da profissão. Esta intervenção contínua revela-se em cada campo de trabalho na definição de protocolos, na salvaguarda de dotações seguras e níveis de educação / formação adequados (Kowalski \& Anthony, 2017).

Pode-se afirmar que a enfermagem está na vanguarda na defesa da qualidade e da segurança dos cuidados, tanto na evidência produzida como na assunção desse papel na linha da frente. No entanto, tais esforços não têm sido acompanhados por medidas concretas (Kowalski \& Anthony, 2017; Hughes, 2018).

Os enfermeiros constituem-se como interlocutores privilegiados na comunicação com a sua equipa, facilitando os processos de melhoria da qualidade dos cuidados e da segurança dos clientes (Carvalho \& Lucas, 2020). Os enfermeiros são os agentes da qualidade dos cuidados prestados e essa qualidade é significativamente influenciada pela forma como o enfermeiro gestor gere o serviço nas suas diferentes dimensões (Fradique \& Mendes, 2013).

Importa assim conhecer a evolução científica em torno da SP, designadamente no que se refere às ERPI.

Bonner, Castle, Men \& Handler (2009) defendiam que existia uma relação entre a CSP e os resultados clínicos. Além disso, equipas com uma CSP mais desenvolvida tendiam a relatar eventos adversos com mais frequência.

Por sua vez, Castle (2011), apresentando um estudo comparativo sobre a cultura de segurança (CS) entre os hospitais com as ERPI nos Estados Unidos da América (USA), concluiu que, em algumas dimensões, a CSP nas ERPI é mais favorável que a CSP nos hospitais, perspetivando uma oportunidade de aprendizagem na assistência à pessoa idosa e, consequentemente, a possibilidade de melhoria dos cuidados.

Os residentes em ERPI, pessoas com múltiplos problemas físicos e cognitivos, constituem uma população com elevado risco para eventos adversos tais como quedas, úlceras de pressão, infeções do trato urinário e erros de medicação (Damery, Flanagan, Rai, \& Combes, 2017)

Em comparação com os hospitais, a CSP em ERPI encontra-se ainda numa fase inicial em muitos países. Além disso, os estudos sobre a SP em ERPI baseiam-se ainda em dimensões relativas à SP em hospitais, carecendo de muitas adaptações considerando as diferenças estruturais das organizações e o perfil dos respetivos utentes (Simmons et al., 2016). 
Realça-se, no entanto, que já se verifica nas ERPI um novo enfoque de melhoria da SP centrado na melhoria das estruturas e dos processos, em vez de culpabilizar os colaboradores e as equipas (Li, Cen, Cai \& Temkin-Greener, 2019).

O erro humano não é inevitável. Atualmente, exige-se um melhor sistema de saúde às lideranças organizacionais. Essas mudanças tornaram imperativas a compreensão da CS e os seus efeitos nos resultados do paciente (DiCuccio, 2015). Esforços na melhoria da CSP em lares de idosos resultam na melhoria da SP e na qualidade do atendimento aos pacientes (Li et al., 2019).

Avaliar a CSP nas organizações possibilita uma eficiente perceção dos aspetos importantes para a SP, permitindo aos gestores definir os esforços para a melhoria (Ree \& Wiig, 2019).

\section{Métodos}

Esta revisão integrativa segue a metodologia de Whittemore e Knafl (2005) e teve como questão orientadora "Qual a evidência científica sobre a cultura de segurança nas estruturas residenciais para pessoas idosas?". Posteriormente procedeu-se à delimitação do projeto de pesquisa, sendo identificados cinco descritores: Casa de saúde, Segurança do doente, Cuidadores, Gestão da segurança, Enfermagem.

Considerou-se a análise de artigos cujos estudos se referissem ao contexto de ERPI ou unidades de cuidados integrados. Os estudos a considerar poderiam visar a cultura de segurança como um todo ou apenas uma dimensão específica, como por exemplo, a sua influência nas infeções do trato urinário.

Foram definidos como critérios de inclusão a publicação dos artigos no intervalo temporal entre os anos 2015 e 2020 e o documento estar disponível em texto completo. Definiu-se também que seriam excluídos os estudos exclusivamente relacionados com o contexto hospitalar.

Nesta revisão optou-se por uma estratégia de pesquisa nas bases de dados eletrónicas CINAHL e MEDLINE, complementada com pesquisas através do Google Scholar e dos repositórios de dissertações. De seguida, foram examinados os títulos, e os resumos. Por fim, aquando da análise integral dos artigos selecionados, foi efetuada uma pesquisa pelas referências bibliográficas desses documentos.

\section{Resultados}

No conjunto das pesquisas efetuadas nas bases de dados CINHAL e MEDLINE, assim como através do Google Scholar e nos repositórios de dissertações, foram identificados 103 estudos. Foram removidos 41 artigos duplicados. Após análises dos títulos e dos resumos foram removidos 33 e 9 artigos respetivamente. Um conjunto de 20 artigos foi analisado na íntegra, sendo removidos ainda 10 artigos. Da análise integral dos artigos, a pesquisa das suas referências permitiu identificar 2 novos artigos selecionáveis. Obteve-se um conjunto final de 12 artigos para integrar a revisão integrativa da literatura, indicado no diagrama prisma, de acordo com Moher, Liberati, Tetzlaff \& Altman (2009). 

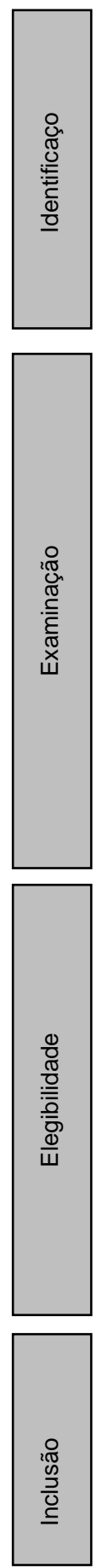

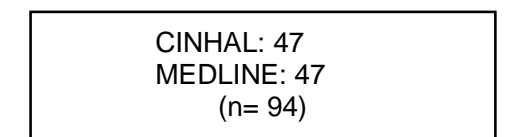

$(n=94)$

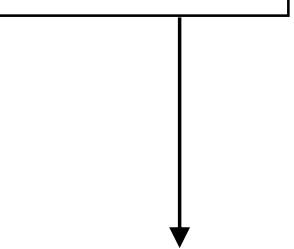

Estudos depois de removidos os duplicados: $(n=62)$

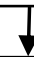

Artigos examinados pelo título: $(n=62)$

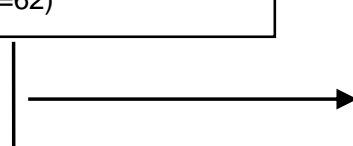

Artigos excluídos pelo título: $(n=33)$ Repositórios de

Dissertações: 3 $(n=9)$

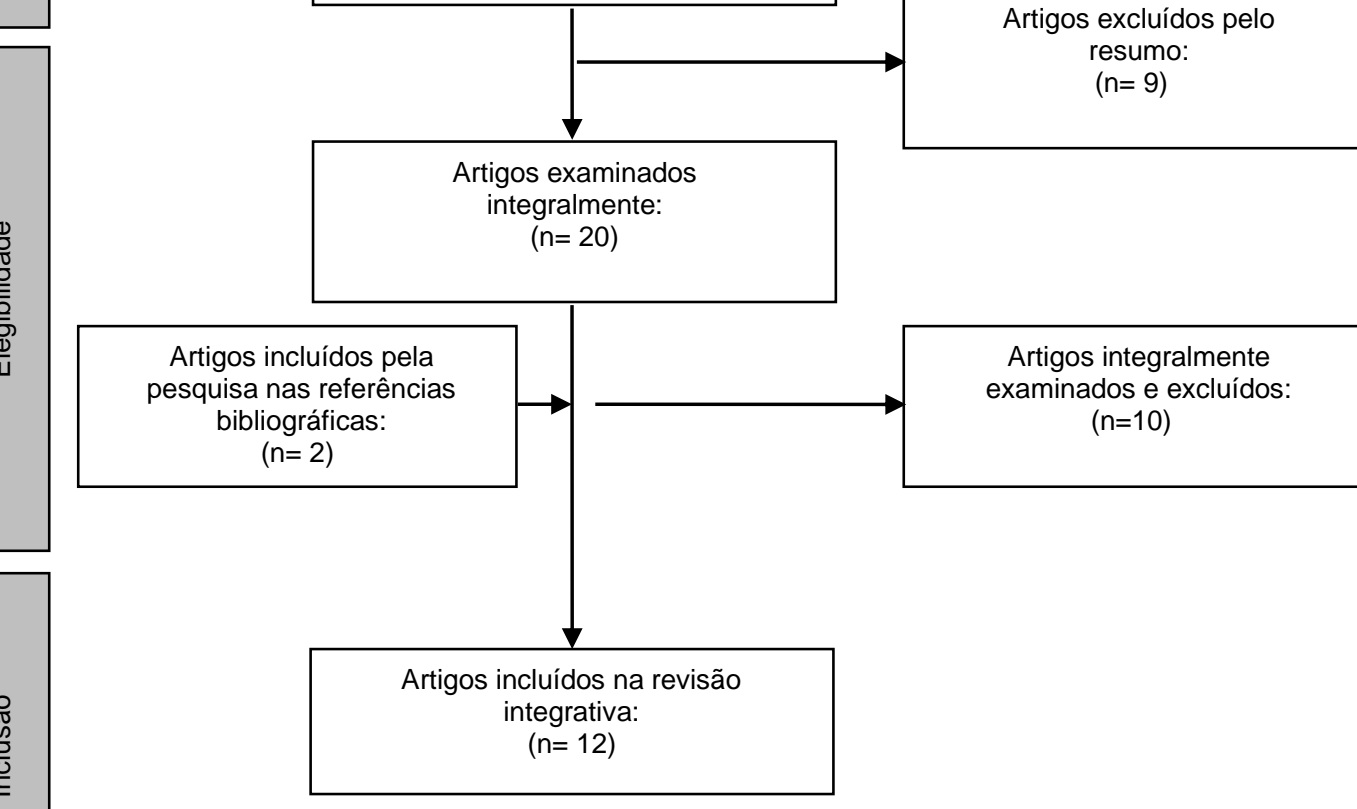

Fig. 1. Diagrama de PRISMA referente ao processo de seleção dos estudos. 
O quadro 1 apresenta uma síntese da análise dos 12 estudos selecionados.

Quadro 1. Quadro-síntese dos estudos incluídos na revisão.

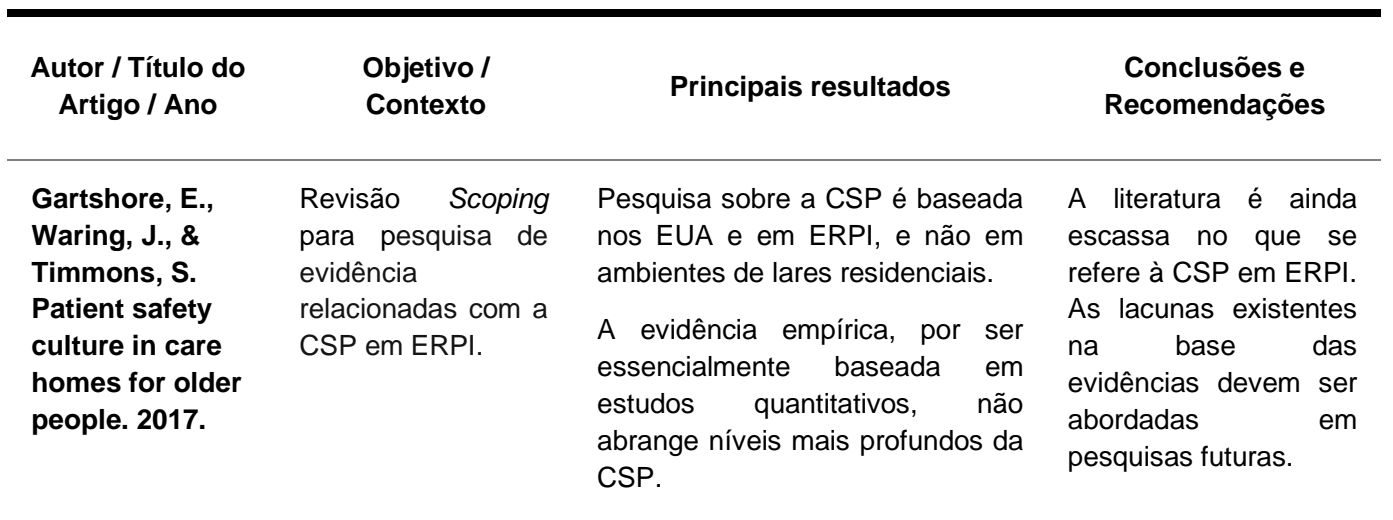

Banaszak-Holl, J., Reichert, H., Todd Greene, M., Mody, L., Wald, H. L., Crnich, C., ... Meddings, J., Do Safety Culture Scores in Nursing Homes. 2017
Estudo com 14.177 participantes para identificar preditores ao nível das instalações e individual da CSP em ERPI (EUA).
Em todos os domínios a avaliação do pessoal auxiliar e de toda a equipa clínica é menos favorável que a dos administradores.
Existe uma grande variabilidade na avaliação da CSP dentro da equipa da ERPI.

Será importante que a CSR seja avaliada na ótica da profissão $e$ não apenas no âmbito da estrutura.

\begin{tabular}{llr}
\hline Bondevik, G., & Investigar as \\
Hofoss, D., & atitudes de \\
Husebø, B., \& & segurança entre os \\
Deilkås, E., & profissionais de \\
Patient safety & saúde em 5 ERPI \\
culture in & noruegueses, \\
Norwegian & usando o Safety \\
nursing homes. & Attitudes \\
2017. & Questionnaire" \\
& (SAQ)
\end{tabular}

\section{Pontuações médias aumentadas significativamente para colaboradores mais velhos e com posição de coordenação para os fatores "clima de trabalho em equipa", "clima de segurança", "satisfação no trabalho" e "condições de trabalho". \\ A formação profissional e a experiência de trabalho não se destacaram das médias para qualquer fator de segurança do paciente.}

Avaliar a CSP pode ajudar os gestores dos lares de idosos na implementação de medidas de melhoria direcionadas.

Sugere pesquisa entre a CSP e a ocorrência de eventos adversos.

\section{Santos, M., A \\ Cultura de \\ Segurança do \\ Cliente nas \\ Unidades de \\ Cuidados \\ Continuados \\ Integrados, \\ 2015.}

Dissertação de Pontuação muito favorável na mestrado - estudo quantitativo.

Aplicação do

NHSPSC da AHRQ em 20 Unidades de Cuidados Continuados Integrados (UCCI) e 86 enfermeiros para avaliar a sua perceção da CSP. apreciação geral da SP. Mais de $93 \%$ afirma que diria aos seus amigos que a sua $\mathrm{UCCl}$ é segura.

Avaliações significativamente favoráveis nas dimensões "Trabalho em equipa", "Feedback e comunicação sobre a existência de incidentes", "Perceção geral da segurança do cliente" e "Expectativas dos superiores hierárquicos em relação à promoção da segurança do cliente".
Existência de pontos fortes e oportunidades de melhoria na CSP. A prioridade emergente de melhoria na dimensão "Resposta não punitiva ao erro" potencia a subnotificação de eventos adversos, constituindo uma obstáculo importante para uma CSC forte. 


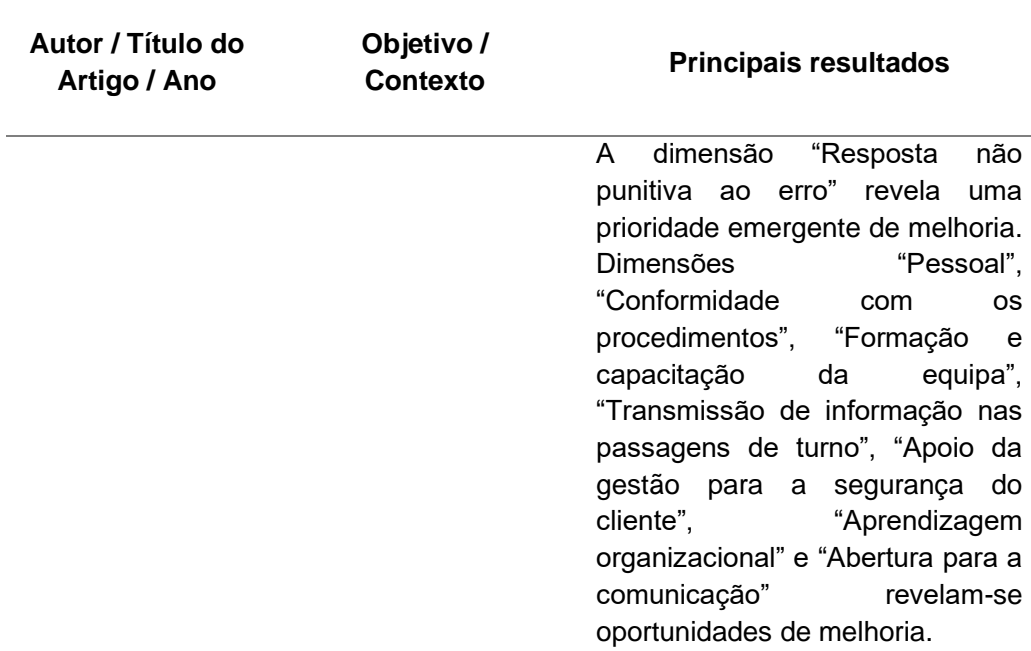

Park, B., Hong, Pesquisar sobre a Verificou-se uma correlação

E., Lim, S., \& relação entre a positiva entre a CSP e as atitudes

Lee, G., Patient

Safety Culture,

Attitude Toward

Falls, and Fall

Prevention

Activities of

Care Workers in

Long-term Care

Facilities. 2015

He, H., Yu, P., Li,

L., Xiao, $X$.,

CSP e as

intervenções de

prevenção de

quedas, incidindo o

estudo em 190

profissionais de

saúde nas ERPI da

Coreia do Sul.

Long, Y., Wang,

L., ... Li, Y.,

Patient safety

culture and

obstacles to

adverse event

reporting in

nursing homes.

2020

\section{em relação às quedas.}

Houve uma correlação significativamente positiva entre as atitudes em relação às quedas e as intervenções de prevenção de quedas.

Investigar, em 79

ERPI chinesas, a

CSP e a sua relação com os obstáculos à notificação de eventos adversos.

le

A atmosfera punitiva e os relatórios de gestão são considerados fortes barreiras à notificação de eventos adversos.

Dimensões "trabalho de equipa" e "conformidade com os procedimentos" são áreas a melhorar.

AHRQ. (2019).
Nursing Home
Survey on
Patient Safety
Culture: 2019

Estudo quantitativo em ERPI sobre CSP: relatório do banco de dados de usuários de 2019.

Amostra com
10499
colaboradores de 191 lares de idosos que têm contacto direto com os residentes.
Conclusões e

Recomendações
Desafia os gestores a abandonar a filosofia punitiva do erro, e promover a conceção de um sistema seguro e transparente.
Dimensões como a "resposta não punitiva a erros", "abertura de comunicação" e "pessoal" com potencial de melhoria.

Dimensões com pontuação mais favorável são "perceções gerais de segurança do residente", "feedback e comunicação sobre incidentes" e "expectativas e ações do supervisor para promover a segurança dos residentes".

A maioria dos colaboradores classificou como excelente ou muito boa SP e $73 \%$ dos colaboradores recomendariam a sua estrutura a amigos.
Os enfermeiros devem melhorar a educação para a segurança do residente desenvolver um sistema de gestão da CSP, que inclua as intervenções de prevenção de quedas.
Sugere a criação de um sistema de relatório de eventos adversos sem barreiras, reduzindo os obstáculos à notificação e criando uma CSP não punitiva. A dimensão pessoal deve ser melhorada. 


\begin{tabular}{|c|c|}
\hline $\begin{array}{l}\text { Autor / Título do } \\
\text { Artigo / Ano }\end{array}$ & $\begin{array}{l}\text { Objetivo / } \\
\text { Contexto }\end{array}$ \\
\hline $\begin{array}{l}\text { Hall, L. H., } \\
\text { Johnson, J., } \\
\text { Watt, I., Tsipa, } \\
\text { A., \& O'Connor, } \\
\text { D. B., Healthcare } \\
\text { staff wellbeing, } \\
\text { burnout, and } \\
\text { patient safety. } \\
2016 .\end{array}$ & $\begin{array}{lr}\text { Revisão sistemática } \\
\text { da lateratura. } \\
\text { Análise a } 46 \\
\text { estudos verifica se } \\
\text { existe associação } \\
\text { entre o bem-estar e } \\
\text { o burnout dos } \\
\text { profissionais } & \text { de } \\
\text { saúde com } & \text { a } \\
\text { segurança } & \text { do } \\
\text { paciente. }\end{array}$ \\
\hline $\begin{array}{l}\text { Simmons, S., } \\
\text { Schnelle, J., } \\
\text { Sathe, N., Slagle, } \\
\text { J., Stevenson, } \\
\text { D., Carlo, M. \& } \\
\text { McPheeters, M. } \\
\text { Defining Safety } \\
\text { in the Nursing } \\
\text { Home Setting: } \\
\text { Implications for } \\
\text { Future } \\
\text { Research. } 2016 .\end{array}$ & $\begin{array}{lr}\text { Revisão } & \text { da } \\
\text { literatura } & \text { para } \\
\text { desenvolver } & \text { uma } \\
\text { agenda } & \text { de } \\
\text { pesquisa } & \text { sobre } \\
\text { segurança } & \text { no } \\
\text { ambiente das } & \text { ERPI } \\
\text { cm } 4 \text { focos: quedas } \\
\text { com lesão, úlceras } \\
\text { de pressão, erros } \\
\text { de medicação e } \\
\text { infeções. }\end{array}$ \\
\hline
\end{tabular}

\title{
Conclusões e \\ Recomendações \\ Principais resultados
}

bem-estar

A maioria dos estudos que avaliaram o bem-estar encontrou uma correlação significativa entre o bem-estar insatisfatório e a pior segurança do paciente.

A maioria dos estudos que avaliaram o burnout encontrou uma associação significativa entre o burnout e a segurança do paciente.

\section{A literatura disponível relata uma} série de intervenções para tratar de eventos adversos nas ERPI.

A complexidade da população das ERPI está refletida nos estudos de pesquisa que demonstram que múltiplos fatores contribuem para os 4 eventos adversos descritos.

\section{insatisfatório e os}

níveis moderados a

altos de burnout

conduzem a resultados

insatisfatórios na

segurança do paciente.

\author{
Importante \\ implementar \\ intervenções \\ direcionadas \\ diretamente para os \\ eventos adversos.
}

Sugere intervenções destinadas a outros alvos tais como perda de peso não intencional, desidratação; incontinência, depressão,

polimedicação, etc..

\begin{tabular}{|c|c|c|c|}
\hline $\begin{array}{l}\text { Abusalem, S., } \\
\text { Polivka, B., } \\
\text { Coty, M., } \\
\text { Crawford, T., } \\
\text { Furman, C., } \\
\text { Alaradi, M., The } \\
\text { Relationship } \\
\text { Between Culture } \\
\text { of Safety and } \\
\text { Rate of Adverse } \\
\text { Events in Long- } \\
\text { Term Care } \\
\text { Facilities. } 2019\end{array}$ & $\begin{array}{lr}\text { Através } & \text { da } \\
\text { aplicação } & \text { do } \\
\text { NHSPSC } & \text { da } \\
\text { AHRQ, avaliar a } & \text { a } \\
\text { relação entre as } \\
\text { dimensões da CS } \\
\text { centrada na pessoa } \\
\text { e a taxa de eventos } \\
\text { adversos } \\
\text { instituições em } \\
\text { longa de } \\
\text { (EUA) duração }\end{array}$ & $\begin{array}{l}\text { A "comunicação" e as } \\
\text { "expectativas do supervisor e } \\
\text { ações que promovam a } \\
\text { segurança dos residentes" foram } \\
\text { as dimensões mais valorizadas. } \\
\text { O aumento da CSP resulta na } \\
\text { diminuição de eventos adversos. } \\
\text { Um maior número de enfermeiros } \\
\text { e de auxiliares nas ERPI um pilar } \\
\text { fundamental para a CSP. }\end{array}$ & $\begin{array}{l}\text { Sugere a necessidade } \\
\text { de construir uma forte } \\
\text { CSP para promover } \\
\text { uma cultura centrada } \\
\text { no residente em ERPI. }\end{array}$ \\
\hline $\begin{array}{l}\text { Desmedt, M.; } \\
\text { Petrovic, M.; } \\
\text { Beuckelaere, P.; } \\
\text { Vandijck, D., } \\
\text { Assessing } \\
\text { Resident Safety } \\
\text { Culture in Six } \\
\text { Nursing Homes } \\
\text { in Belgium. } 2018\end{array}$ & $\begin{array}{lr}\text { Através } & \text { da } \\
\text { aplicação } & \text { do } \\
\text { NHSPSC da } & \text { dHRQ, avaliar a } \\
\text { AHRQ em 6 ERPI do } \\
\text { CSP } \\
\text { norte da Bélgica. }\end{array}$ & $\begin{array}{l}\text { Dimensão " pessoal" com } \\
\text { pontuação baixa, relacionada com } \\
\text { a rotatividade dos colaboradores. } \\
\text { Pontuação elevada nas } \\
\text { dimensões "trabalho de equipa"," } \\
\text { resposta não punitiva aos erros", } \\
\text { "transferências", " feedback e } \\
\text { comunicação } \\
\text { sobre incidentes" e "abertura de } \\
\text { comunicação". } \\
\text { Os gestores com pontuações } \\
\text { significativamente mais altas que }\end{array}$ & $\begin{array}{l}\text { As perceções } \\
\text { da CSP }\end{array}$ \\
\hline
\end{tabular}
a equipa de enfermagem. 


\begin{tabular}{|c|c|c|c|}
\hline $\begin{array}{l}\text { Autor / Título do } \\
\text { Artigo / Ano }\end{array}$ & $\begin{array}{l}\text { Objetivo / } \\
\text { Contexto }\end{array}$ & Principais resultados & $\begin{array}{c}\text { Conclusões e } \\
\text { Recomendações }\end{array}$ \\
\hline $\begin{array}{l}\text { Buljac- } \\
\text { Samardžic, M., \& } \\
\text { Van Woerkom, } \\
\text { M. Improving } \\
\text { quality and } \\
\text { safety of care in } \\
\text { nursing homes } \\
\text { by team support } \\
\text { for strengths } \\
\text { use: A survey } \\
\text { study. } 2018\end{array}$ & $\begin{array}{lr}\begin{array}{l}\text { Investigar } \\
\text { relações }\end{array} & \text { as } \\
\text { carga de trabalho e } \\
\text { o apoio da equipe } \\
\text { na qualidade } & \text { da } \\
\text { assistência } & \text { e } \\
\text { segurança } & \text { do } \\
\text { paciente em } & \text { ERPI. } \\
\text { Participaram } & \text { no } \\
\text { estudo } & 497 \\
\text { colaboradores } & \text { em } \\
74 \text { equipes de } & 7 \\
\text { ERPI, na Holanda. }\end{array}$ & $\begin{array}{l}\text { Mais de } 95 \% \text { dos colaboradores } \\
\text { consideram a sua carga de } \\
\text { trabalho problemática ou muito } \\
\text { elevada. } \\
\text { Mais de } 85 \% \text { identifica algum } \\
\text { apoio ou um forte apoio no seu } \\
\text { esforço individual. }\end{array}$ & $\begin{array}{l}\text { Sugere melhorias na } \\
\text { área do pessoal e que, } \\
\text { na medida do possível, } \\
\text { sejam aproveitados os } \\
\text { pontos fortes de cada } \\
\text { colaborador. } \\
\text { Recomenda } \\
\text { desenvolvimento de } \\
\text { mais estudos. }\end{array}$ \\
\hline
\end{tabular}

\section{Discussão}

Com a inclusão de 12 estudos na presente pesquisa, entre os quais nove estudos primários e três revisões da literatura, foi possível perceber qual a atual evidência científica sobre a CSP nas ERPI, um pouco por todo o mundo.

Nos últimos anos houve um grande desenvolvimento de estudos acerca da CSP nas ERPI (Gartshore, Waring \& Timmons, 2017). Impulsionados pelos EUA, outros países europeus e asiáticos têm desenvolvido estudos que permitem extrair uma razoável perspetiva no âmbito a CSP nas estruturas para pessoas idosas (Bondevik, Hofoss, Husebø \& Deilkås, 2017; Santos, 2015; Park, Hong, Lim \& Lee, 2015; He et al., 2020; Desmedt, Petrovic, Beuckelaere \& Vandijck, 2018).

Apesar dos avanços referidos, as evidências relativas à CSP nas ERPI são ainda limitadas e incompletas. A baixa representatividade dos estudos estará relacionada com as diferenças nas tipologias e dimensões das estruturas entre cada país, mas também na grande variação dos problemas que essas estruturas revelam (Gartshore et al., 2017).

Um dos desafios para a segurança dos cuidados está relacionado com a qualificação dos colaboradores das ERPI. Grande parte dos prestadores de cuidados diretos não possui qualificações para tal (Gartshore et al., 2017). Estes factos remetem para a necessidade de desenvolver evidências mais robustas e profundas, tais como estudos qualitativos, que permitam dar a conhecer a realidade da cultura organizacional e sistémica (Gartshore et al., 2017). Outro aspeto que parece transversal na CSP nas ERPI é o facto dos colaboradores mais envolvidos nos cuidados e, naturalmente, mais próximos dos pacientes, revelarem classificações mais baixas do que os administradores (Banaszak-Holl et al., 2017; Santos, 2015).

Num estudo em ERPI da Noruega, colaboradores com categorias mais altas apresentam melhores pontuações em dimensões como "trabalho de equipa", "clima de segurança" e "satisfação no trabalho" (Bondevik et al., 2017). Ao contrário, Banaszak-Holl et al. (2017), nos EUA, refere que os colaboradores mais antigos tendem a apresentar também classificações mais baixas que os mais novos.

Os administradores, com um papel fundamental nos processos de melhoria da qualidade, com avaliações habitualmente muito favoráveis quanto à CSP, deverão aproximar-se dos cuidados diretos de modo a identificarem as lacunas que afetam a segurança dos clientes (Banaszak-Holl et al., 2017; Santos, 2015). 
No estudo norueguês, em que a maioria dos participantes eram enfermeiros ou auxiliares, Bondevik et al. (2017) encontraram avaliações muito favoráveis quanto à comunicação e colaboração entre os elementos das equipas dos cuidados diretos. Contudo, encontrou pontuações mais baixas na comunicação e colaboração com os médicos e com os administradores.

Qualquer intervenção para melhoria da segurança que ignore as caraterísticas dos colaboradores e o modo como os cuidados diretos e diários são prestados estará condenada ao fracasso (Simmons et al., 2016).

A prevenção e a adequada notificação de eventos adversos parecem estar intimamente ligadas à CSP nos lares de idosos. Num estudo na Coreia do Sul, Park et al. (2015) identificam uma correlação positiva entre a CSP e a atenção perante as quedas, assim como as intervenções para a sua prevenção. Ainda assim, a complexidade da população das ERPI parece justificar melhor os múltiplos fatores que contribuem para os eventos adversos ocorridos nos lares (Simmons et al., 2016).

Referindo que na China a incidência de eventos adversos nas ERPI é muito maior que nos hospitais, $\mathrm{He}$ et al. (2020) sublinham que os relatos de eventos adversos são fundamentais para a SP. Nas ERPI estudadas por He et al. (2020) a perceção geral da $\mathrm{SP}$ é francamente favorável. No entanto, verifica-se um nível moderado na perceção da CSP e nos relatos de eventos adversos. À semelhança de outros estudos, dimensões como o "trabalho de equipa" e "conformidade com os procedimentos" revelam pontuações baixas, verificando-se grande precaridade nos colaboradores, com cargas de trabalho elevadas, havendo mesmo a tentação de optar por atalhos ou ignorar procedimentos (He et al., 2020).

Simmons et al. (2016) sustentam que, devido a vários motivos, as ERPI revelam uma grande dificuldade em mitigar ou evitar os fatores causais de eventos adversos nos residentes. Assumindo que esta realidade é diferente da hospitalar, integrar as dificuldades com a complexidade inerente à população e com as caraterísticas da estrutura e dos seus colaboradores pode ajudar na definição de cuidados baseadas na evidência com objetivos mais realistas (Simmons et al., 2016). Também BuljacSamardžic \& Van Woerkom (2018) defendem que a maioria dos eventos adversos parece estar mais relacionado com as condições dos pacientes.

Num estudo para avaliar a relação entre a CSP e a taxa de eventos adversos em ERPI nos EUA, Abusalem et al. (2019) encontraram dados compatíveis com o estudo da Agency for Healthcare Research and Quality (AHRQ). A maioria dos 252 participantes, além de terem uma boa ou excelente apreciação geral da SP, recomendaria a sua estrutura a amigos. Verificou-se também que o aumento da disponibilidade de cuidados de enfermagem e o aumento da CSP resultam numa influência significativa na diminuição de úlceras de pressão, ITU e quedas nas ERPI (Abusalem et al., 2019).

He et al. (2020) recomendam a criação de um banco chinês de relatos de eventos adversos em ERPI que permita o acesso a dados confiáveis, que forneça evidências para reduzir barreiras à notificação de eventos adversos e que promova a CSP. Esta poderá ser uma iniciativa de grande interesse noutros países.

Dificuldades na comunicação ao nível da gestão e a atmosfera punitiva evidenciam-se como barreias relevantes e transversais à notificação de eventos adversos. Os enfermeiros gestores terão um papel importante na definição de um caminho mais expedito, seguro, transparente e menos punitivo na comunicação de eventos adversos, no qual a equipa possa partilhar os erros e aprender (He et al., 2020; Santos, 2015; $A H R Q, 2019)$.

Numa avaliação da CSP em 6 ERPI do norte da Bélgica, Desmedt et al. (2018) confirmam a tendência de apreciações mais favoráveis por parte dos gestores, ao obterem pontuações significativamente mais elevadas que os enfermeiros na maioria das dimensões. 
Ao estudar a CSP de enfermeiros em UCCI portuguesas, Santos (2015) verifica avaliações muito favoráveis nas dimensões "perceção geral da segurança do cliente", no "feedback e comunicação sobre a existência de incidentes" e nas "expectativas dos superiores hierárquicos em relação à promoção da segurança do cliente". A avaliação favorável revela-se também na pergunta se "considera a UCCI segura / recomendaria aos seus amigos?".

Nas UCCl portuguesas, dimensões como "pessoal", "conformidade com os procedimentos" e "formação e capacitação da equipa", não revelando pontuações negativas, constituem claras oportunidades de melhoria. Já a dimensão "resposta não punitiva a erros" apresenta-se como prioridade emergente de melhoria (Santos, 2015), facto que potenciará a subnotificação de erros.

Num estudo de dois anos apresentado em 2019, com abordagem à generalidade dos funcionários de $191 \mathrm{ERPI}$, num total de 10499 colaboradores, a AHRQ encontra avaliações mais favoráveis para as dimensões "perceções gerais de segurança dos residentes", "feedback e comunicação sobre incidentes" e "expectativas e ações do supervisor para promover a segurança dos residentes". Por sua vez, verifica-se um potencial de melhoria nas dimensões "trabalho de equipa", "abertura à comunicação" e "resposta não punitiva a erros" (AHRQ, 2019).

Desmedt et al., (2018) defendem que, ao contrário dos restantes estudos, os colaboradores das ERPI abrangidas apresentam uma avaliação favorável na dimensão "resposta não punitiva a erros". Ainda assim, também aqui, a equipa de saúde considera que os processos na comunicação de erros são difíceis. Outras dimensões que apresentam pontuações significativamente favoráveis neste estudo são comparáveis aos restantes estudos apresentados, nomeadamente "feedback e comunicação sobre a existência de incidentes" e "perceção geral da segurança dos residentes" (Desmedt et al., 2018). Também os colaboradores das ERPI na Bélgica evidenciam uma pontuação baixa na dimensão "pessoal" (Desmedt et al., 2018).

O bem-estar insatisfatório, o esgotamento físico e níveis de burnout moderados a elevados apresentam uma correlação significativa com piores índices de SP. Importa criar ambientes de trabalho seguros e favoráveis à saúde mental dos colaboradores de modo a melhorar a segurança do paciente (Hall et al., 2016).

As baixas pontuações encontradas nos diferentes estudos no que se refere à dimensão "pessoal" podem ser causadas por diversos fatores. Num estudo nos Países Baixos, Buljac-Samardžic \& Van Woerkom (2018) concluíram que a maioria dos colaboradores vê a sua carga de trabalho como problemática. Ainda assim, esse entendimento não parece interferir na perceção da qualidade dos cuidados e na segurança do paciente. Pelo efeito motivacional, o apoio da equipa na utilização de pontos fortes de cada elemento parece ser uma boa estratégia na relação entre as necessidades de trabalho e o desempenho (Buljac-Samardžic \& Van Woerkom, 2018).

O desenvolvimento de competências dos colaboradores das ERPI, seja qual for a sua profissão e nível académico, deverá ser uma aposta das estruturas que interpretem a SP como um fator crítico de sucesso (Banaszak-Holl et al., 2017; Park et al., 2015; He et al., 2020; AHRQ, 2019). É também necessária a definição clara do papel dos diferentes elementos da equipa. Ao contrário dos hospitais, a esmagadora maioria dos cuidados são assegurados por auxiliares, que garantem o acompanhamento diário dos residentes por longos períodos de tempo (Simmons et al., 2016).

O grande pilar dessa CS é, certamente, o conjunto de colaboradores que, num ambiente de grande exigência física e emocional, precisa de motivação, sustentabilidade e formação adequada. Os enfermeiros gestores devem desenvolver intervenções de melhoria tanto nos recursos humanos como nos procedimentos de modo a incrementar a qualidade dos cuidados e a segurança do residente (He et al., 2020; Park et al., 2015, Abusalem et al., 2019; Santos, 2015). 
Vol. 8 | Investigação Qualitativa em Saúde: Avanços e Desafios

Apesar dos avanços das últimas décadas, são necessários mais e diferentes estudos sobre todas as dimensões da CSP nas ERPI (Gartshore et al., 2017; Banaszak-Holl et al., 2017; Santos, 2015; Bondevik et al., 2017; AHRQ, 2019; Buljac-Samardžic et al., 2018).

\subsection{Limitações da Revisão}

A escassez de estudos referentes a ERPI, principalmente fora dos EUA, constituiu uma limitação significativa para a presente revisão. Ainda assim, foi possível obter uma perspetiva geral da CSP nas ERPI.

\section{Conclusões}

Além da literatura americana, a evidência científica referente à CSP nas ERPI é ainda escassa, designadamente em Portugal. Contudo, foi possível analisar um conjunto de estudos que permite uma visão geral desta problemática.

A CSP nas ERPI apresenta inúmeras dimensões e pode ser influenciada por múltiplos fatores. A complexidade dos estados de saúde e funcional da pessoa idosa e os problemas estruturais das instituições parecem comprometer significativamente a segurança dos residentes.

Parece claro que a qualidade da assistência nas ERPI, não só a dos cuidados, como a de todos os serviços prestados nas ERPI é influenciada pelo comportamento da generalidade dos seus colaboradores, assumindo assim um caráter multiprofissional. Esta dimensão revela-se na abrangência da população estudada pela generalidade dos investigadores.

A natureza das dimensões com avaliações menos favoráveis, assim como as características dos colaboradores das ERPI, evidenciam a necessidade do recurso à metodologia qualitativa nos estudos a desenvolver.

É fundamental a criação de um novo paradigma de segurança do residente em ERPI. Os enfermeiros em geral e os enfermeiros gestores em particular podem ter uma intervenção preponderante nesse novo paradigma. É também essencial o desenvolvimento de estudos sobre a realidade das ERPI portuguesas.

A presente revisão pode constituir um ponto de partida no planeamento dessa intervenção com vista uma melhoria CSP e, por conseguinte, da qualidade dos cuidados nas ERPI.

\subsection{Conflito de Interesses}

Os autores declaram não existir qualquer conflito de interesse. 


\section{Referências}

Abusalem, S., Polivka, B., Coty, M. B., Crawford, T. N., Furman, C. D., \& Alaradi, M. (2019). The relationship between culture of safety and rate of adverse events in long-term care facilities. Journal of Patient Safety, 1-6. DOI: 10.1097/pts.0000000000000587;

AHRQ. (2019). Nursing home survey on patient safety culture: User Dtabase Report. Disponível em: https://www.ahrq.gov/sites/default/files/wysiwyg/sops/surveys/2019-nhsops-dbreportparti.pdf;

Banaszak-Holl, J., Reichert, H., Todd Greene, M., Mody, L., Wald, H. L., Crnich, C., Meddings, J. (2017). Do safety culture scores in nursing homes depend on job role and ownership? Results from a national survey. Journal of the American Geriatrics Society, 65(10), 2244 2250 ;

Bondevik, G. T., Hofoss, D., Husebø, B. S., \& Deilkås, E. C. T. (2017). Patient safety culture in Norwegian nursing homes. BMC Health Services Research, 17(1), 1-11. DOI: 10.1186/s12913-017-2387-9;

Bonner, A., Castle, N., Men, A. \& Handler, S. (2009). Certified nursing assistants perceptions of nursing home patient safety culture: Is there a relationship to clinical outcomes? Journal of the American Medical Directors Association, 10(1), 11-20. DOI: 10.1016/j.jamda.2008.06.004;

Buljac-Samardžic, M. \& Van Woerkom, M. (2018). Improving quality and safety of care in nursing homes by team support for strengths use: A survey study. PLoS ONE, 13(7), 1-17. DOI: 10.1371/journal.pone.0200065;

Carvalho, M. C., \& Lucas, P. R. (2020). A eficácia da prática do enfermeiro líder clínico - Revisão sistemática da literatura. Millenium, 2(11), 57-64. DOI: 10.29352/mill0211.06.00274;

Castle, N., Perera, S., Ferguson, J., Handler, S. \& Wagner, L. (2011). Comparing the safety culture of nursing homes and hospitals. Journal of Applied Gerontology, 30(1), 22-43. DOI: 10.1177/0733464809353603;

Desmedt, M., Petrovic, M., Beuckelaere, P., Vandijck, D. (2018). Assessing resident safety culture in six nursing homes in belgium, Journal of Patient Safety (00). DOI: 10.1097/PTS.0000000000000476;

DiCuccio, M. (2015) The relationship between patient safety culture and patient outcomes, Journal of Patient Safety: (11) 3. 135-142 DOI: 10.1097/PTS.0000000000000058;

Fradique, M., \& Mendes, L. (2013). Efeitos da liderança na melhoria da qualidade dos cuidados de enfermagem. Revista de Enfermagem Referência, III Série(10), 45-53. DOI: 10.12707/riii12133;

Gartshore, E., Waring, J., \& Timmons, S. (2017). Patient safety culture in care homes for older people: A scoping review. BMC Health Services Research, 17(1), 752. DOI: 10.1186/s12913 017-2713-2

He, H., Yu, P., Li, L., Xiao, X., Long, Y., Wang, L., ... Li, Y. (2020). Patient safety culture and obstacles to adverse event reporting in nursing homes. Journal of Nursing Management. DOI: 10.1111/jonm.13098;

Hughes, R. G. (2018). Overview of patient safety and quality of care. In Kelly, P., Vottero, B. \& Christie-Mcauliffe, C., Introduction to Quality and Safety Education for Nurses (pp. 3-38).New York: Springer Publishing Company. DOI: 10.1891/9780826123855.0001

Kowalski, S. L., Anthony, M., (2017) Nursing's evolving role in patient safety american. American Journal of Nursing: 117(2). 34-48. DOI: 10.1097/01.NAJ.0000512274.79629.3c;

Li, Y., Cen, X., Cai, X., \& Temkin-Greener, H. (2019). Perceived patient safety culture in nursing homes associated with "nursing home compare" performance indicators. Medical Care, 57(8), 641-647. DOI: 10.1097/MLR.0000000000001142;

Moher, D., Liberati, A., Tetzlaff, J., Altman, D. (2009). The PRISMA group. Preferred reporting items for systematic reviews and meta-analyses: The PRISMA statement. Annals of Internal Medicine, 151: 264-269. DOI: 10.7326/0003-4819-151-4-200908180-00135; 
Park, B. H., Hong, E.Y., Lim, S.O., \& Lee, G.S. (2015). Patient safety culture, attitude toward falls, and fall prevention activities of care workers in long-term care facilities. Journal of Korean Gerontological Nursing, 17(3), 166-174. DOI: 10.17079/jkgn.2015.17.3.166;

Ree, E., \& Wiig, S. (2019). Employees' perceptions of patient safety culture in Norwegian nursing homes and home care services. BMC Health Services Research, 19(1), 1-8. DOI: 10.1186/s12913-019-4456-8;

Santos, S. (2015). A Cultura de segurança do cliente nas unidades de cuidados continuados integrados (Dissertação de mestrado não publicada). Escola Superior de Enfermagem de Lisboa, Lisboa. Recuperada da base de dados: Repositórios Científicos de Acesso Aberto de Portugal;

Simmons, S., Schnelle, J., Sathe, N., Slagle, J., Stevenson, D., Carlo, M. \& McPheeters, M. (2016) Defining safety in the nursing home setting: Implications for future research. Journal of the American Medical Directors Association, 17(6), 473-481. DOI: 10.1016/j.jamda.2016.03.005.

Whittemore, R., \& Knafl, K. (2005). The integrative review: Updated methodology. Journal of Advanced Nursing, 52(5), 546-553. DOI: 10.1111/j.1365-2648.2005.03621.x. 